\title{
BMJ Open Cohort profile of the Biomarkers of Acute Serious Illness in Children (BASIC) study: a prospective multicentre cohort study in critically ill children
}

\author{
Yael Feinstein, ${ }^{1,2}$ Jennifer Claire Walker, ${ }^{1}$ Mark J Peters, ${ }^{1,3}$ Simon Nadel, ${ }^{4}$ \\ Nazima Pathan, ${ }^{5}$ Naomi Edmonds, ${ }^{6}$ Jethro Herberg, ${ }^{7}$ Myrsini Kaforou, ${ }^{7}$ \\ Victoria Wright, ${ }^{7}$ Michael Levin, ${ }^{7}$ Padmanabhan Ramnarayan ${ }^{4,8}$
}

To cite: Feinstein Y, Walker JC Peters MJ, et al. Cohort profile of the Biomarkers of Acute Serious IIIness in Children (BASIC) study: a prospective multicentre cohort study in critically ill children. BMJ Open 2018;8:e024729. doi:10.1136/ bmjopen-2018-024729

- Prepublication history and additional material for this paper are available online. To view these files, please visit the journal online (http://dx.doi. org/10.1136/bmjopen-2018024729).

Received 18 June 2018 Revised 3 August 2018 Accepted 26 September 2018

Check for updates

(c) Author(s) (or their employer(s)) 2018. Re-use permitted under CC BY-NC. No commercial re-use. See rights and permissions. Published by BMJ.

For numbered affiliations see end of article.

Correspondence to Professor Michael Levin; m.levin@imperial.ac.uk

\section{ABSTRACT}

Purpose Despite significant progress, challenges remain in the management of critically ill children, including early identification of infection and organ failure and robust early risk stratification to predict poor outcome. The Biomarkers of Acute Serious IIIness in Children study aims to identify genetic and biological pathways underlying the development of critical illness in infections and organ failure and those leading to poor outcome (death or severe disability) in children requiring emergency intensive care. Participants We recruited a prospective cohort of critically ill children undergoing emergency transport to four paediatric intensive care units (PICUs) in Southeast England between April 2014 and December 2016. Findings to date During the study period, 1017 patients were recruited by the regional PICU transport team, and blood and urine samples were obtained at/ around first contact with the patient by the transport team. Consent for participation in the study was deferred until after PICU admission and 674 parents/carers were consented. Further samples (blood, urine, stool and throat swabs) were collected after consent. Samples were processed and stored for genomic, transcriptomic, proteomic and metabolomic analyses. Demographic, clinical and laboratory data at first contact, during PICU stay and at discharge, were collected, as were detailed data regarding infectious or non-infectious aetiology. In addition, 115 families have completed 12-month validated follow-up questionnaires to assess quality of life and child behaviour. The first phase of sample analyses (transcriptomic profiling) is currently in progress.

Future plans Stored samples will be analysed using genomic, proteomic and metabolic profiling. Advanced bioinformatics techniques will be used to identify biomarkers for early diagnosis of infection, identification of organ failure and risk stratification to predict poor outcome (death/severe disability).

Trial registration number NCT03238040.

\section{INTRODUCTION}

Each year, nearly 20000 children are admitted to paediatric intensive care units (PICUs) in the UK. ${ }^{1}$ Considerable progress has been
Strengths and limitations of this study

- The BASIC study comprises a large cohort of critically ill children admitted to multiple PICUs in England, with biological samples linked to detailed demographic and clinical data regarding the intensive care course as well as 12-month follow up data collected using validated quality of life and behavioural questionnaires.

- A careful process of clinical phenotyping has been undertaken to classify patients into infectious and non-infectious disease aetiologies. Samples have been stored for future proteomic and genomic analyses.

- The process of deferred consent meant that severely ill patients recruited to the study who died before consent could be obtained, as well as children discharged from the PICU before families were approached for consent, were excluded, limiting the generalisability of our study findings.

- We were unable to classify nearly a quarter of the patients by their infection aetiology most likely due to the use of a clinical definition as the gold standard for classification. Although we attempted to collect samples from prior to interventions, a significant proportion of children had been mechanically ventilated and treated with antibiotics by the time the transport team arrived at the local hospital.

made in the understanding of paediatric critical illness and how best to provide organ support to improve outcomes, and mortality for children admitted to intensive care has reduced dramatically over the past four decades. ${ }^{2}$ However, significant gaps remain in our current knowledge. In particular, shortterm outcomes of emergency admissions to PICU remain suboptimal (mortality of $7 \%-8 \%$ ), and relatively little is known about longer term morbidity in survivors. ${ }^{34}$

Severe infection is a leading cause of life-threatening illness in children. Yet, early 
identification of infection and further discrimination of whether it is bacterial (treatable with antibiotics) or viral remain a significant challenge in the acute/critical care setting. ${ }^{56}$ Consequently, most, if not all, critically ill children are started and then remain on broad-spectrum antibiotics for several days; prolonged antibiotic use increases the risk of side-effects, increases cost and contributes to development of antimicrobial resistance. ${ }^{78}$ A second challenge is that development of organ failure and progression to irreversible multiple organ failure is the final common pathway that leads to death or severe disability in children with critical illness, yet current approaches are reactive rather than proactive, using clinical and biochemical abnormalities to diagnose established organ failure rather than identify incipient organ failure. ${ }^{9-11}$ Finally, while the future of interventional clinical trials in intensive care crucially hinges on early risk stratification, current severity of illness scores are designed for use in populations of patients rather than in individuals, and are designed to predict mortality, an uncommon and increasingly less relevant outcome of intensive care. ${ }^{12} 13$

The potential of multiomics technologies in unravelling the complex interactions between genes, proteins and biochemical reactions in other areas of medicine provides a strong indication that in order to fill existing gaps in our current knowledge in critical care, a comprehensive systems biology approach can be successfully applied to the study of large, diverse groups of sick children at an early stage of critical illness. ${ }^{14-21}$ The Biomarkers of Acute Serious Illness in Children (BASIC) study is a multicentre collaborative study to identify genetic and biological pathways underlying the development of critical illness, organ failure and poor outcome (death or severe disability) in children requiring emergency intensive care.

\section{COHORT DESCRIPTION}

\section{Study aims}

The three key study aims were to: (1) develop a gene expression biomarker of bacterial infection which can be further developed as a simple point-of-care test to distinguish infections from other causes, and bacterial from viral infection, in critically ill children; (2) discover and validate biomarkers for early accurate detection of single and multiple organ failure that can predict organ failure earlier than the existing scores which are based on clinical data and laboratory tests that are already deranged; (3) identify biomarker-based strategies to help risk stratify critically ill children with diverse aetiologies at an early stage based on their predicted outcome in intensive care.

\section{Study cohort}

BASIC is a multicentre, prospective, observational study involving a regional PICU transport service and four PICUs in southeast England (Great Ormond Street Hospital, St Mary's Hospital and the Royal London Hospital in London, and Addenbrookes' Hospital in Cambridge). Eligible patients were critically ill children aged 0-16 years requiring emergency transfer by the Children's Acute Transport Service (CATS) to a study PICU, with an indwelling catheter (arterial and/or central venous catheter for blood sampling and urinary catheter for urine sample collection). This simple and practical criterion has been shown in previous work to enrich the sample by selecting patients at high predicted risk of mortality, the median risk of death being $10 \%$ in the group of patients with an indwelling catheter, as compared with $8 \%$ in all transported children (as per CATS audit data). Children transported to other PICUs or non- PICU destinations, premature newborns (under 36-week corrected gestational age) and those with a known do-not-attempt-resuscitation order in place were excluded.

\section{Patient recruitment and informed consent}

All transported children were screened for eligibility by medical and nursing staff from the CATS team at first faceto-face patient contact. Eligible patients were recruited to the study and blood \pm urine samples were collected from indwelling catheters, coinciding with routine clinical sampling. Ethical approval was granted for consent to be deferred (also known as 'research without prior consent') due to the emergency setting, similar to previous clinical trials in paediatric emergency care; deferred consent has been shown to be acceptable to clinicians as well as participants. ${ }^{22-24} \mathrm{~A}$ written informed consent was obtained by the research team in the admitting PICU from parents/ guardians once the child's condition had stabilised, usually within 24-48 hours following PICU admission. As per ethical approval provided for deferred consent in our study, carers of children who died prior to approach for consent were excluded from the study. Parents/guardians could consent for full participation in the study (analysis of samples and clinical data already collected, further sample collection on the day of consent and data collection until the child's discharge from PICU, and contact to complete follow-up questionnaires at 12 months after PICU admission, if appropriate) or partial participation (analysis of samples and clinical data already collected but no further involvement), or refuse consent (samples and clinical data already collected to be discarded).

\section{Sample collection}

Sample collection and transport procedures were devised based on previous work, the UK Biobank operating procedures and information from related sample handling validation studies (see table 1) ${ }^{25}{ }^{26}$ Blood and urine samples were collected at two points of time: during transport to PICU (time point 1) and after consent was obtained (time point 2 ). Time point 1 samples were transported on ice packs $\left(4^{\circ} \mathrm{C}\right)$ to the admitting PICU where they were processed by the local research team. Samples were anonymised by means of a unique study number assigned by the CATS team to each recruited patient. Processed samples were stored at $-80^{\circ} \mathrm{C}$ at individual sites and later transported to a central laboratory for further study analyses. 
Table 1 Samples and time points at which collected, processing and storage instructions, and total numbers of samples available

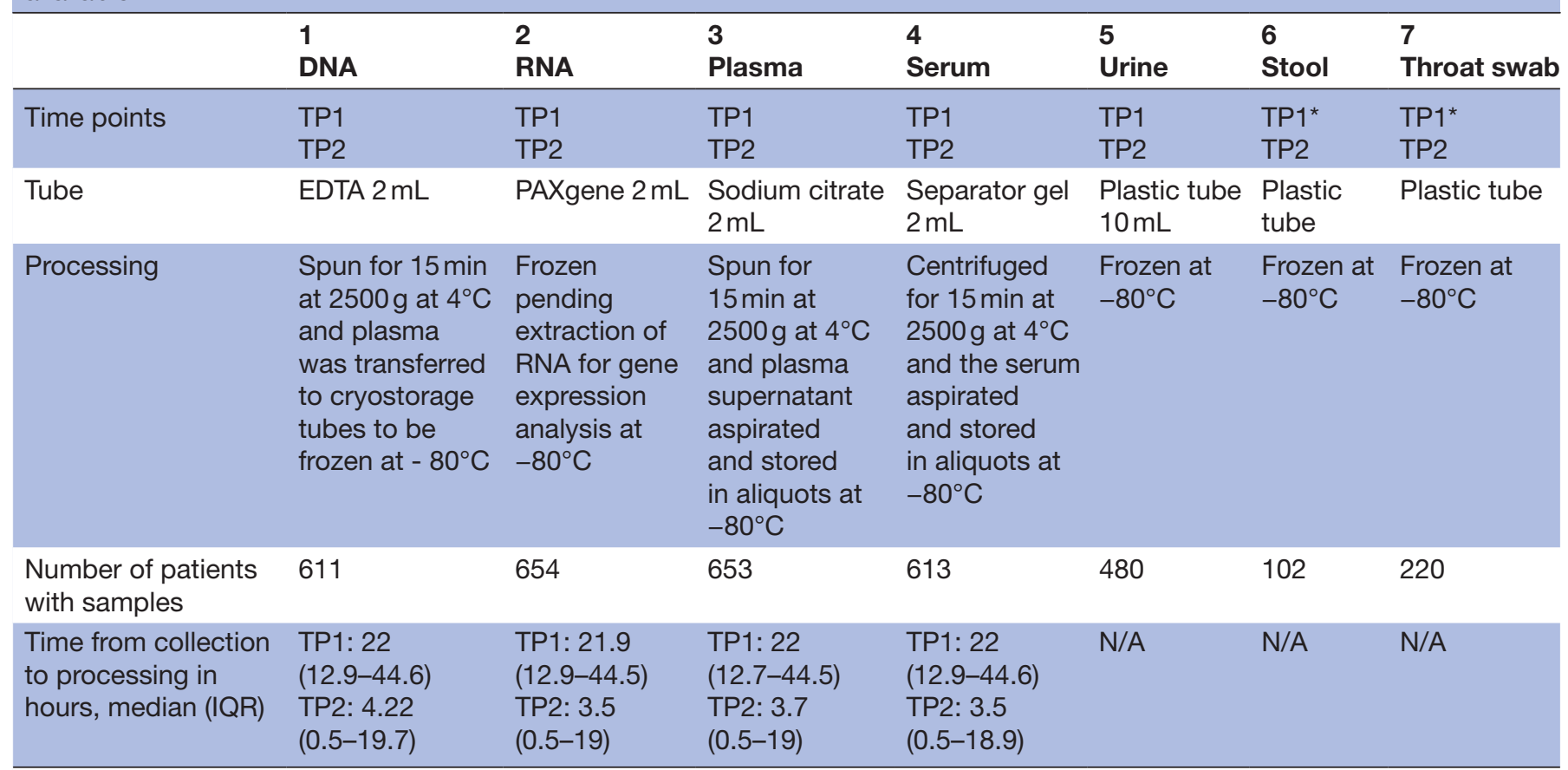

*Stool and throat swab TP1 samples were collected at paediatric intensive care unit (PICU) admission rather than during transport. TP1, time point 1 (during transport); TP2, time point 2 (after PICU admission, once consent had been obtained).

\section{Clinical data}

A standardised case report form and data collection manual with definitions and rules were produced for research staff at each PICU. Clinical data collected covered the key stages of the patient's pathway-intensive care referral and transport, PICU course and outcome. As shown in the online supplementary table 1 and in tables 2-4, detailed clinical phenotyping information was collected, including reason for PICU referral/admission (infection, trauma, neurological, cardiac, respiratory and other), severity of illness (Paediatric Index of Mortality 2, PIMS-2 score), severity of organ failure (PEdiatric Logistic Organ Dysfunction, PELOD-2 score) on days 0, 1, 2 and 3, and outcome at discharge from PICU (death, severe disability). In addition, we used screening questions regarding general health and functional status and validated age- questionnaires (Child Behaviour Checklist and Pediatric Quality of Life Inventory, PedsQL) to assess the child's adaptive behaviour, general quality of life and functional outcome at 12 months after PICU admission, if appropriate.

\section{Outcome measures}

Primary

1. Diagnosis of bacterial infection by laboratory tests (culture, molecular diagnostics) within the first 28 days or prior to PICU discharge.

2. Multiorgan failure-failure of two or more organs using the PELOD-2 score within the first 28 days or prior to PICU discharge.
3. Poor outcome defined as mortality or development of a new severe disability at intensive care unit discharge.

\section{Secondary}

1. Long-term health-related quality of life assessed at 12 months by the age-appropriate PedsQL questionnaire completed by parent proxy.

2. Long-term behavioural outcome assessed at 12 months by the age-appropriate Child Behaviour Checklist completed by parent proxy.

\section{Sample size}

No formal sample size calculations were performed, but we aimed to recruit adequate numbers of patients with different reasons for intensive care admission as well as those experiencing the primary outcomes (50-80 patients per group of interest). According to previous audit data, we estimated that we could recruit up to 800 patients over the study period.

\section{Sample analyses}

In the first phase of sample analyses, we will address the first key study aim, namely the development of a gene expression biomarker to distinguish infections from other causes, and bacterial from viral infection. We will not limit our analyses to a preselected list of biomarkers, instead a hypothesis-free approach will be pursued. Whole blood was collected in PAXgene blood RNA tubes (PreAnalytiX), and later extracted using PAXgene blood RNA kits (PreAnalytiX). RNA was shipped to the Oxford Genomics Center for analysis on HumanHT-12 V.4 


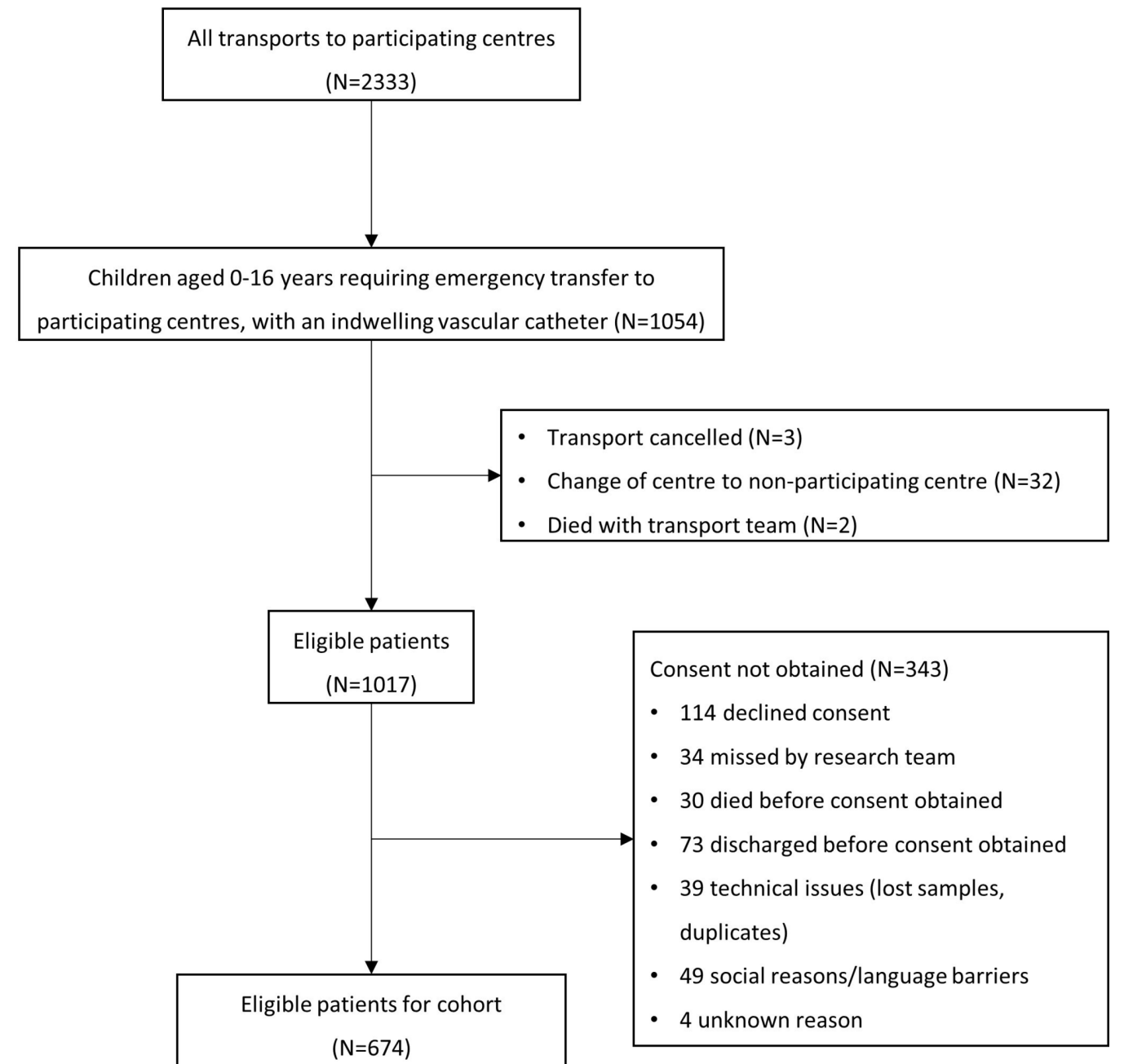

Figure 1 Flow chart of recruitment to the Biomarkers of Acute Serious Illness in Children study.

expression Beadarrays (Illumina). Other samples will be stored for future analyses, and in further phases, we will consider the use of genomics, rapid throughput proton nuclear magnetic resonance spectroscopy and mass spectrometry techniques to explore the role of protein biomarkers, as well as undertaking metabolomic analyses. DNA will be used for genotyping of genes implicated in sepsis or critical illness, enabling linking of genetic and transcriptomic information.

\section{Study organisation}

The study was conducted under the leadership of a BASIC study management group comprising the investigators with overall responsibility for protocol design, study conduct and publication. Imperial College serves as the coordinating centre for sample and informatics analyses.

\section{FINDINGS}

During the study period of 33 months (1 April 2014-7 December 2016), 2333 children were transported to the participating PICUs by the CATS team. As shown in figure 1, although 1054 patients were recruited to the BASIC study by the CATS team, 37 were ineligible since they were not eventually admitted to a study PICU. Consent for participation was obtained from parents/ guardians of 674 children $(66.1 \%$ of the 1017 children admitted to a study PICU). The main reason for not obtaining consent from patients was death or discharge of the patient from the PICU prior to being approached by the research team $(137 / 1017,13.5 \%)$. Parents/guardians refused consent in 114/1017 (11.2\%).

Cohort characteristics are shown in table 2 . An overview of samples and time points at which collected, processing and storage instructions, and total numbers of samples stored is summarised in table 1.

Details regarding the PICU stay and short-term outcomes for the children enrolled are shown in Table 3.

At the end of the PICU stay, study patients were classified into one of six groups based on their infection status as a reason for admission (non-infectious condition; definite bacterial, definite viral, probable bacterial and probable viral infections; and unable to determine infection status) as shown in table 4 .

We used an algorithm as described previously to perform this classification (online supplementary figure 1). ${ }^{27}$ The classification was performed by two investigators 


\begin{tabular}{|c|c|}
\hline Variable & n (\%) \\
\hline \multirow{2}{*}{ Male gender } & 367 (54.5) \\
\hline & $13(1.9)$ \\
\hline \multicolumn{2}{|l|}{ Ethnicity } \\
\hline Asian & $77(11.4)$ \\
\hline Black & $53(7.9)$ \\
\hline White & $312(46.3)$ \\
\hline Other & $40(5.9)$ \\
\hline Missing & $192(28.5)$ \\
\hline \multicolumn{2}{|l|}{ Age group } \\
\hline 0-1 month & $112(16.6)$ \\
\hline $1-11$ months & $148(22)$ \\
\hline $1-4$ years & $212(31.5)$ \\
\hline $5-12$ years & $132(19.6)$ \\
\hline$>12$ years & $55(8.2)$ \\
\hline Missing & $15(2.2)$ \\
\hline Consanguinity & $22(3.3)$ \\
\hline Missing & $203(30.1)$ \\
\hline Comorbidities present & $342(51)$ \\
\hline Missing & $42(6.2)$ \\
\hline \multicolumn{2}{|l|}{ Comorbidities* } \\
\hline Respiratory & $110(16.3)$ \\
\hline Cardiac & $73(10.8)$ \\
\hline Neurological & $134(19.9)$ \\
\hline Genetic/syndrome & $62(9.2)$ \\
\hline Metabolic/endocrine & $33(4.9)$ \\
\hline Haematological/oncological & $13(1.9)$ \\
\hline Multisystem disorder & $8(1.2)$ \\
\hline Other & $103(15.3)$ \\
\hline Gestational age, median (IQR)† & $38(36-40)(n=245)$ \\
\hline
\end{tabular}

Time from onset of symptoms to first contact with transport team

\begin{tabular}{|c|c|}
\hline Less than 6 hours & $126(18.7)$ \\
\hline $6-24$ hours & $169(25.1)$ \\
\hline 24-72 hours & $168(24.9)$ \\
\hline $3-7$ days & $123(18.2)$ \\
\hline$>7$ days & $73(10.8)$ \\
\hline Missing & $15(2.2)$ \\
\hline \multicolumn{2}{|c|}{ PCPC status (prior to PICU admission) } \\
\hline Normal & $434(64.4)$ \\
\hline Mild disability & $38(5.6)$ \\
\hline Moderate disability & $52(7.7)$ \\
\hline Severe disability & $64(9.2)$ \\
\hline Missing & $86(12.8)$ \\
\hline \multicolumn{2}{|c|}{ POPC status (prior to PICU admission) } \\
\hline Normal & 433 (64.2) \\
\hline
\end{tabular}

Continued

\begin{tabular}{ll}
\hline Table 2 Continued & \\
\hline Variable & $\mathbf{n}(\%)$ \\
\hline Mild disability & $38(5.6)$ \\
Moderate disability & $57(8.5)$ \\
Severe disability & $62(9.2)$ \\
Missing & $84(12.5)$ \\
Acuity during transport to PICU & \\
\hline Invasively ventilated & $573(85)$ \\
Inhaled nitric oxide & $25(3.7)$ \\
Received>40 mL/kg fluid bolus & $51(7.6)$ \\
Vasoactive agents & $260(38.6)$ \\
Blood product transfusion & $13(1.9)$ \\
$\begin{array}{l}\text { Maximum vasoactive-inotropic } \\
\text { score, median (IQR) }\end{array}$ & $20(10-65)(\mathrm{n}=243)$ \\
\hline Fixed and dilated pupils & $6(0.9)$ \\
PELOD-2 score, median (IQR) & $6(4-8)(\mathrm{n}=674)$ \\
PIM-2 mortality risk, median (IQR) & $3.8 \%(1.4-5.3)(\mathrm{n}=674)$ \\
\hline
\end{tabular}

*Same child may have comorbidities of different groups. †Gestational age was collected only for children<2-year old. PCPC, paediatric cerebral performance category; PELOD-2, PEdiatric Logistic Organ Dysfunction; PICU, paediatric intensive care unit; PIM-2, Paediatric Index of Mortality-2; POPC, paediatric overall performance category.

(JCW and YF) and a random sample of $10 \%$ of records was checked by one investigator (PR). Any queries arising during this classification were resolved by discussion with PR.

\section{Patient and public involvement}

Parents of children previously transported to an intensive care unit were involved in the pilot testing of the 12-month follow-up questionnaires and provided input into the choice of the questionnaires. Although there was no formal involvement of parents/public in the development of the research question and outcome measures chosen, clinicians within the research team identified the research question and outcomes as being important for patients from informal discussions with patients/parents.

\section{Strengths and limitations}

The BASIC study comprises a large cohort of critically ill children admitted to multiple PICUs in England, with biological samples linked to detailed demographic and clinical data regarding the intensive care course as well as 12-month follow-up data collected using validated quality of life and behavioural questionnaires. A careful process of clinical phenotyping has been undertaken to classify patients into infectious and non-infectious disease aetiologies. Samples have been stored for future proteomic and genomic analyses.

\section{Recruitment in an emergency setting}

One of the unique strengths of this cohort is the timing and extensive nature of sample and clinical data 
Table 3 Course during intensive care stay $(\mathrm{N}=674)$

\begin{tabular}{ll}
\hline Variable & $\mathbf{n ~ ( \% )}$ \\
\hline $\begin{array}{l}\text { Type of admission } \\
\text { Unplanned, after surgery }\end{array}$ & $19(2.8)$ \\
\hline Unplanned, other & $650(96.5)$ \\
\hline Missing & $5(0.7)$ \\
\hline $\begin{array}{l}\text { Number of hours invasively ventilated, } \\
\text { median (IQR) }\end{array}$ & $\begin{array}{l}87(40-168) \\
(\mathrm{n}=669)\end{array}$ \\
\hline $\begin{array}{l}\text { Number of hours on vasoactive agents, } \\
\text { median (IQR) }\end{array}$ & $\begin{array}{l}0(0-48) \\
(\mathrm{n}=644)\end{array}$ \\
\hline $\begin{array}{l}\text { Number of hours on inhaled nitric oxide, } \\
\text { mean (SD) }\end{array}$ & $\begin{array}{l}4.18(19.74) \\
(\mathrm{n}=37)\end{array}$ \\
\hline Number of hours on ECLS, mean (SD) & $3.93(30.07)$ \\
& $(\mathrm{n}=15)$ \\
\hline Number of hours on CRRT, mean (SD) & $2.6(26.87)$ \\
$(\mathrm{n}=12)$
\end{tabular}

PICU discharge status

\begin{tabular}{|ll}
\hline Died & $27(4.0)$ \\
\hline Alive & $636(96)$ \\
\hline Missing & $11(1.6)$ \\
\hline Discharge location & \\
\hline Home & $18(2.7)$ \\
\hline Hospice & $5(0.7)$ \\
\hline Other & $10(1.5)$ \\
\hline Other hospital & $312(46.3)$ \\
\hline Same hospital & $291(43.2)$ \\
\hline Missing & $37(5.6)$ \\
\hline Discharge POPC & \\
\hline Normal & $358(53.1)$ \\
\hline Mild disability & $54(8)$ \\
\hline Moderate disability & $46(6.8)$ \\
\hline Severe disability & $70(10.4)$ \\
\hline Coma/vegetative state & $1(0.1)$ \\
\hline Missing & $145(21.5)$ \\
\hline Discharge PCPC & \\
\hline Normal & $363(53.9)$ \\
\hline Mild disability & $54(8)$ \\
\hline Moderate disability & $41(6.1)$ \\
\hline Severe disability & $69(10.2)$ \\
\hline Coma/vegetative state & $1(0.1)$ \\
\hline Brain death & $1(0.1)$ \\
\hline Missing & $145(21.5)$ \\
\hline
\end{tabular}

Continued
Table 3 Continued

\begin{tabular}{ll}
\hline Variable & $\mathbf{n ~ ( \% )}$ \\
\hline Ventilator free days at day 30, median (IQR) & $\begin{array}{l}25(22-27) \\
(\mathrm{n}=642)\end{array}$ \\
PICU free days at day 30, median (IQR) & $\begin{array}{l}24(19-26) \\
(\mathrm{n}=642)\end{array}$
\end{tabular}

PCPC, paediatric cerebral performance category; PICU, paediatric intensive care unit; POPC, paediatric overall performance category.

collection in a population of critically ill children. In contrast to similar previous cohorts, we chose to standardise the timing of sample collection to the point of first contact with an intensive care team early in the course of critical illness, rather than after PICU admission. This provides the opportunity to collect biological samples at the earliest time point as practically possible during critical illness, when the confounding effect of a dynamically evolving pathophysiology and the influence of critical care interventions such as mechanical ventilation and vasoactive agent treatment may be ameliorated. In addition, even though patients may first present to hospitals at various stages of their critical illness, by standardising sample collection to the earliest possible time point, we attempted to generate a more homogenous cohort than possible if patients were recruited at various time points after PICU admission.

\section{Consent model}

Recognising that asking parents/guardians to consent to a research study in a busy emergency setting (where the priority for the transport team is to perform lifesaving interventions) may result in a less than ideal informed consent process, we chose to defer written consent until after PICU admission, when the child's clinical condition had stabilised. We provided parents

Table 4 Classification of reasons for paediatric intensive care unit admission $(n=669)$

\begin{tabular}{ll}
\hline Classification & $\mathbf{n}(\%)$ \\
\hline Definite bacterial infection & $61(9.1)$ \\
\hline Definite viral infection & $146(22)$ \\
\hline Probable bacterial infection & $60(8.9)$ \\
\hline Probable viral infection & $27(4.0)$ \\
\hline Inconclusive for bacterial or viral infection & $159(23.6)$ \\
\hline Non-infectious condition & $215(31.9)$ \\
\hline Type of non-infectious conditions: & $\mathrm{n}=215$ \\
\hline Respiratory/airway & $45(19.5)$ \\
\hline Cardiac & $57(27.4)$ \\
\hline Neurological & $51(23.7)$ \\
\hline Trauma/head injury & $22(10.2)$ \\
\hline Endocrine/metabolic & $13(6.0)$ \\
\hline Other & $28(13.1)$ \\
\hline
\end{tabular}


with the option for either full or partial participation in the study, or for refusal of consent. Although we saw a low proportion of refusal of consent $(\sim 10 \%)$, practical challenges of providing 7 days a week research nurse cover on the units to approach recruited participants meant that a significant proportion were not approached for consent resulting in collected samples being destroyed.

\section{Limitations}

The process of deferred consent resulted in bias: 31 children who were recruited to the study died before consent could be obtained from families, which, as per approved ethical procedures, resulted in their exclusion from the study. Due to this exclusion, severely ill patients were excluded limiting the generalisability of our study findings. Similarly, 70 children were recruited to the study but were discharged from the PICU before families were approached for consent, resulting in their exclusion. Despite the high level of detail contained in the clinical database, we found that four patients were excluded due to missing data on key data such as their outcome and infection status. In addition, we were unable to classify nearly a quarter of the patients by their infection aetiology most likely due to the use of a clinical definition as the gold standard for classification. Although we attempted to collect samples from prior to interventions, a significant proportion of children had been mechanically ventilated and treated with antibiotics by the time the transport team arrived at the local hospital.

\section{Author affiliations}

${ }^{1}$ Paediatric Intensive Care Unit, Great Ormond Street Hospital for Children NHS Foundation Trust, London, UK

${ }^{2}$ Department of Paediatrics, Faculty of Health Sciences, Ben-Gurion University of the Negev, Beer-Sheva, Israel

${ }^{3}$ UCL Great Ormond Street Institute of Child Health, University College London, London, UK

${ }^{4}$ Paediatric Intensive Care, St Mary's Hospital, Imperial College Healthcare NHS Trust, London, UK

'Paediatrics Intensive Care, Addenbrookes' Hospital, Cambridge University Hospital NHS Foundation Trust, Cambridge, UK

${ }^{6}$ Paediatric Critical Care Unit, Royal London Hospital, Barts Health NHS Trust, London, UK

${ }^{7}$ Department of Medicine, Section for Paediatrics, Imperial College London, London, UK

${ }^{8}$ Children's Acute Transport Service, Great Ormond Street Hospital for Children NHS Trust, London, UK

Acknowledgements The authors thank the research teams in the participating units and transport service without whom this study would not have been possible. Children's Acute Transport Service: Leanne Branighan and Ali Clayton-Payne; Great Ormond Street Hospital: Katie Hardy, Lauran 0'Neill, Sarah Caley, Eugenia Abalake, Francesca Standing and Amy Jones; St Mary's Hospital: Amina Abdulla and Sobia Mustafa; Addenbrookes Hospital: Deborah White and Jenna Ridout; Royal London Hospital: Maysze Chang, Nicolene Plaatjies and Bessie Crone.

Collaborators Requests for collaboration, either sample analyses or clinical data analyses using the BASIC database, can be made in writing to the chief investigator/Imperial College once the primary analyses planned have been completed. The BASIC study management group will evaluate the request and if written approval is provided, a prespecified analytical plan will be requested.
Contributors MJP, SN, NP, NE, JH, MK, VW, ML and PR designed the study, facilitated and coordinated the samples and data collection. YF, JCW, MJP, SN, NP, NE and PR obtained the clinical data. YF, JCW and PR performed clinical phenotyping. YF and PR performed the analysis and drafted the manuscript. JCW, MJP, SN, NP, NE, JH, MK, VW and ML approved the manuscript, made significant contributions to the manuscript and have read and approved the final version of it.

Funding The study was funded by the Great Ormond Street Hospital Children's Charity (ref V1401).

Competing interests None declared.

Patient consent Obtained.

Ethics approval Ethical approval was provided by the NRES Committee East Midlands-Nottingham 2 (ref: 13-EM-0399). The study is managed according to the Department of Health Research Governance Framework, and the Medical Research Council Guidelines for Good Research Practice, Good Clinical Practice in Clinical Trials and Medical Research Involving Children. Indemnity is provided by NHS Indemnity scheme for the conduct, design and management of the study.

Provenance and peer review Not commissioned; externally peer reviewed.

Data sharing statement Requests for collaboration, either sample analyses or clinical data analyses using the BASIC database, can be made in writing to the chief investigator/Imperial College once the primary analyses planned have been completed.

Open access This is an open access article distributed in accordance with the Creative Commons Attribution Non Commercial (CC BY-NC 4.0) license, which permits others to distribute, remix, adapt, build upon this work non-commercially, and license their derivative works on different terms, provided the original work is properly cited, appropriate credit is given, any changes made indicated, and the use is non-commercial. See: http://creativecommons.org/licenses/by-nc/4.0/.

\section{REFERENCES}

1. Paediatric Intensive Care Network (PICANet). National report of the Paediatric Intensive Care Audit Network, January 2011-December 2013. Leeds 2014.

2. Namachivayam P, Shann F, Shekerdemian L, et al. Three decades of pediatric intensive care: Who was admitted, what happened in intensive care, and what happened afterward. Pediatr Crit Care Med 2010;11:549-55.

3. Ramnarayan P, Thiru K, Parslow RC, et al. Effect of specialist retrieval teams on outcomes in children admitted to paediatric intensive care units in England and Wales: a retrospective cohort study. Lancet 2010;376:698-704.

4. Agbeko RS, Burns JP, Peters MJ. Tools for revealing uncomfortable truths? Measuring child-centred health-related quality of life after paediatric intensive care. Intensive Care Med 2015;41:1330-2.

5. Thompson MJ, Van den Bruel A. Diagnosing serious bacterial infection in young febrile children. BMJ 2010;340:c2062.

6. Brent AJ, Lakhanpaul M, Thompson M, et al. Risk score to stratify children with suspected serious bacterial infection: observational cohort study. Arch Dis Child 2011;96:361-7.

7. Ostrowsky B, Banerjee R, Bonomo RA, et al. Infectious diseases physicians: Leading the way in antimicrobial stewardship. Clin Infect Dis 2018;66:995-1003.

8. Le Doare K, Nichols AL, Payne H, et al. Very low rates of cultureconfirmed invasive bacterial infections in a prospective 3-year population-based surveillance in Southwest London. Arch Dis Child 2014;99:526-31.

9. Leteurtre S, Martinot A, Duhamel A, et al. Validation of the paediatric logistic organ dysfunction (PELOD) score: prospective, observational, multicentre study. Lancet 2003;362:192-7.

10. Sweney JS, Poss WB, Grissom CK, et al. Comparison of severity of illness scores to physician clinical judgment for potential use in pediatric critical care triage. Disaster Med Public Health Prep 2012;6:126-30.

11. Matics TJ, Sanchez-Pinto LN. Adaptation and validation of a pediatric sequential organ failure assessment score and evaluation of the sepsis-3 definitions in critically ill children. JAMA Pediatr 2017;171:e172352.

12. Straney L, Clements A, Parslow RC, et al. Paediatric index of mortality 3: an updated model for predicting mortality in pediatric intensive care ${ }^{\star}$. Pediatr Crit Care Med 2013;14:673-81.

13. Pollack MM, Patel KM, Ruttimann UE. The pediatric risk of mortality III-Acute Physiology Score (PRISM III-APS): a method of assessing 
physiologic instability for pediatric intensive care unit patients. J Pediatr 1997;131:575-81.

14. Wong HR, Cvijanovich NZ, Anas N, et al. Improved risk stratification in pediatric septic shock using both protein and mRNA biomarkers. PERSEVERE-XP. Am J Respir Crit Care Med 2017;196:494-501.

15. Mickiewicz B, Vogel HJ, Wong HR, et al. Metabolomics as a novel approach for early diagnosis of pediatric septic shock and its mortality. Am J Respir Crit Care Med 2013;187:967-76.

16. Correia GD, Wooi Ng K, Wijeyesekera A, et al. Metabolic profiling of children undergoing surgery for congenital heart disease. Crit Care Med 2015;43:1467-76.

17. Sweeney TE, Azad TD, Donato M, et al. Unsupervised analysis of transcriptomics in bacterial sepsis across multiple datasets reveals three robust clusters. Crit Care Med 2018;46:915-25.

18. Valenzuela-Sánchez F, Valenzuela-Méndez B, Rodríguez-Gutiérrez JF, et al. Personalized medicine in severe influenza. Eur J Clin Microbiol Infect Dis 2016;35:893-7.

19. Friggeri $A$, Cazalis MA, Pachot $A$, et al. Decreased CX3CR1 messenger RNA expression is an independent molecular biomarker of early and late mortality in critically ill patients. Crit Care 2016;20:204.

20. Herberg JA, Kaforou M, Wright VJ, et al. Diagnostic test accuracy of a 2-transcript Host RNA signature for discriminating bacterial vs viral infection in febrile children. JAMA 2016;316:835-45.
21. Kaforou M, Herberg JA, Wright VJ, et al. Diagnosis of bacterial infection using a 2-transcript host RNA signature in febrile infants 60 days or younger. JAMA 2017;317:1577-8.

22. Woolfall K, Frith $\mathrm{L}$, Dawson $\mathrm{A}$, et al. Fifteen-minute consultation: an evidence-based approach to research without prior consent (deferred consent) in neonatal and paediatric critical care trials. Arch Dis Child Educ Pract Ed 2016;101:49-53.

23. Woolfall K, Frith L, Gamble C, et al. How experience makes a difference: practitioners' views on the use of deferred consent in paediatric and neonatal emergency care trials. BMC Med Ethics 2013;14:45.

24. Harron K, Woolfall K, Dwan K, et al. Deferred consent for randomized controlled trials in emergency care settings. Pediatrics 2015; 136:e1316-e1322.

25. Elliott P, Peakman TC. The UK Biobank sample handling and storage protocol for the collection, processing and archiving of human blood and urine. Int J Epidemiol 2008;37:234-44.

26. Peakman TC, Elliott P. The UK Biobank sample handling and storage validation studies. Int J Epidemiol 2008;37:i2-6.

27. Herberg JA, Kaforou M, Wright VJ, et al. Diagnostic test accuracy of a 2-Transcript Host RNA signature for discriminating bacterial vs viral infection in febrile children. JAMA 2016;316:835-45. 